\title{
A closer look at entrepreneurial intentions
}

\author{
Mihaela Mikić • Tin Horvatinović* • Ivan Turčić \\ Faculty of Economics \& Business Zagreb, University of Zagreb, Zagreb, Croatia
}

Received: 10 December 2019

Revised: 2 April 2020

Accepted: 4 May 2020

\begin{abstract}
This paper tests the initial Shapero-Sokol model of an entrepreneurial event, as well as expands it through the use of quadratic and moderating effects. Structural equation modelling is applied to a sample of undergraduate students in Croatia that completed a questionnaire in 2019. Findings show that perceived desirability and perceived feasibility have a positive impact on entrepreneurial intentions, whereas the propensity to act has a negative effect. A closer look reveals that there are other significant effects in the model as well. Quadratic effect is positive for perceived desirability and perceived feasibility, while negative for propensity to act. Lastly, perceived feasibility positively moderates the relations for both perceived desirability and propensity to act on entrepreneurial intentions.
\end{abstract}

Keywords: entrepreneurial intentions; Shapero-Sokol model of entrepreneurial event; SMEs JEL Classification Codes: L26, A20

\section{Introduction}

Different approaches have been taken to enhance the understanding of what causes individuals to found a venture. The trait approach used numerous characteristics of an entrepreneur and then compared it to non-entrepreneurs (Zhao and Seibert, 2006). Another approach adopted from the field of psychology is known as the intention-based approach. The intention-based models attempt to predict a certain behaviour by claiming that intentions are a directinfluence of behaviour. In other words, intentions are the best predictor of behaviour and they are defined as the level of willingness of a person to perform a certain behaviour.

One of these models, namely the Shapero-Sokol model of the entrepreneurial event (Shapero and Sokol, 1982), is used in this study to determine what causes individuals to take entrepreneurial actions. This is examined by employing an empirical analysis on cross-section data, through questionnaire format distributed in 2019, of undergraduate economic students. The data is then analysed using structural equation modelling.

\footnotetext{
* Corresponding author. E-mail: thorvatinovic@ net.efzg.hr.

Citation: Mikić, M., Horvatinović, T., and Turčić, I. (2020) A closer look at entrepreneurial intentions, Economics and Business Letters, 9(4), 361-369.
}

DOI: $10.17811 /$ ebl.9.4.2020.361-369 
This paper has several goals. First is to test the relations between constructs of the ShaperoSokol model to see whether or not there will be discrepancies between this study and the predominant findings of other studies. Furthermore, the moderating effects of the constructs in the Shapero-Sokol model have been neglected in research. So, in this study, a moderation effect is proposed and empirically examined that is not found in the literature. In addition, a moderation effect that has been examined once in the literature has also been tested to give it further empirical support. Finally, nonlinear effects between the constructs have been tested since testing these effects will give further insight into the dynamics of relations between the constructs. Also, this study is a response to a call made by scholars to test nonlinear relations given their hypothesized "too-much-of-a-good-thing" principle.

\section{Literature review}

According to the Shapero-Sokol model, for an individual to have strong entrepreneurial intentions, he/she must believe that the identified business opportunity is credible and they must experience some event that pushes them to carry out a certain behaviour. On the first point, the perceived credibility of a business opportunity rests upon the perceived desirability and perceived feasibility. In other words, the more an individual sees entrepreneurship as a viable career option and the stronger he/she believes their capacity to manage a successful business, the stronger their entrepreneurial intentions will be (Shapero and Sokol, 1982).

With regards to the notion of an event, Shapero and Sokol (1982) postulate that individuals are in a state of inertia and an event is required to force them to take action. This concept is operationalized in propensity to act construct. Following the concept of propensity to act, the stronger an individual inclination to act upon a business opportunity, the stronger are his/her entrepreneurial intentions (Shapero and Sokol, 1982). Thus, all three proposed antecedents of entrepreneurial intentions, perceived desirability, perceived feasibility and propensity to act, will have a positive impact on entrepreneurial intentions. Further empirical studies found support for these relations (Krueger et al. 2000; Ranga et al. 2019), thus it is expected that these relations will hold in this study.

To the best of our knowledge, no study has examined whether or not these relations change with the respective levels of all three predictors of entrepreneurial intentions, even though there is a call for business researches, by invoking "too-much-of-a-good-thing" principle (Grant and Schwartz, 2011), to include quadratic effects in their models to achieve a deeper understanding on the hypothesized relations (Pierce and Aguinis, 2013). This principle states that all positive characteristics of an individual have a cost and at some point the cost will surpass the benefits, leading to a negative effect on higher levels of any characteristic. However, extrapolating from the Shapero-Sokol model, one would expect stronger impacts of those antecedents on their higher levels. Also, ancillary theories give support for a positive quadratic effect of all three components of the model. Herzberg's dual-factor theory states that one set of career choice facets determine whether or not an individual has job satisfaction (motivational factors), while another set determines whether or not an individual has job dissatisfaction (hygiene factors) (Herzberg, 1966). According to this theory, once the hygiene factors are satisfied (e. g. relations with others) there is an increasing incremental effect of motivational factors (e. g. achievement) on job satisfaction. Since an entrepreneurial career can fulfil hygiene factors and especially motivational factors, there will be an incremental increase in perceived desirability of an entrepreneurial career on entrepreneurial intentions. With regards to perceived feasibility, research has shown that entrepreneurs tend to be overconfident in their abilities (Busenitz and Barney, 1997). In addition, overconfidence is associated with entrepreneurial intentions of students 
(Bernoster et al., 2018). From these results, it follows that those students who have entrepreneurial intentions have very high perceived feasibility, so a positive incremental effect is expected. In other words, a positive quadratic effect is hypothesized. The support for the positive quadratic effect comes from the proactivity literature since proactivity is linked to propensity to act (Erikson, 2001). Proactivity can be defined as a persons' inclination to changing and affecting his environment and is positively associated with entrepreneurial intentions (Bateman and Crant, 1993). For individuals with a high proactive personality, their perceived demandability fit has increased with job complexity and this effect is nonlinear with a positive sign (Chung-Yan and Butler, 2011). From this result, it can be conceptualized that the effect of propensity to act will on entrepreneurial intentions will increase with its respective level since an entrepreneurial career choice is of high complexity. In other words, a positive quadratic effect is expected.

Finally, perceived feasibility is employed as a moderator variable. Intention-based models do not prohibit testing moderating effects and some have called for testing these effects (Krueger and Kickul, 2006). Few authors developed models based on the variables of the original Shapero-Sokol model to test for interaction effects. Krueger (2009) proposed a model (with the addition of variables that are not part of the Shapero-Sokol model) where propensity to act is used as a moderator and this effect was subsequently empirically tested and confirmed (Esfandiar et al., 2019). Others (Fitzsimmons and Douglas, 2011) have demonstrated that there is a significant interaction effect between perceived feasibility and perceived desirability. From this, it follows that the research of interaction effects of the variables in the Shapero-Sokol model is scarce. Consequently, two interaction effects are tested in the proposed model, namely the interaction effect between perceived feasibility and perceived desirability and between perceived feasibility and propensity to act. Perceived feasibility is chosen rather than the other variables given the already acquired knowledge of using self-efficacy (a construct highly interconnected to perceived feasibility) as a moderator in entrepreneurship research (Newman et al., 2019). The expected sign for the interaction effect between perceived feasibility and perceived desirability is negative given the results from the Fitzsimmons and Douglas (2011) study which used regulatory focus theory as their theoretical basis. However, the opposite sign is anticipated for the interaction between perceived feasibility and propensity to act. As was already mentioned, propensity to act is a concept that is theoretically linked to proactivity, which when in interaction with perceived self-efficacy leads individuals' to set higher goals (Phillips et al., 2012). Since founding a company can be considered a high reaching goal, a positive effect is expected on the moderation of perceived feasibility between propensity to act and entrepreneurial intentions.

The conceptual model, with the hypothesized signs of the effects, is displayed in figure 1.

\section{Research methodology and results}

The sample consists of undergraduate students who were taking an Entrepreneurship course at the Faculty of Economics and Business in Zagreb. They were given an online questionnaire before a class that was before analysed and completed by other faculty members to improve it. Students filled out the questionnaire at the beginning of the summer semester in 2019. In total, 223 students completed the questionnaire. A 5-point Likert scale was used rather than the 7point Likert scale because it is more understandable and less confusing for students (Jenkins and Taber, 1977). There were no missing values due to the restrictive nature of the digital questionnaire. By screening the data, five responses were labelled as unengaged, given that the standard deviation of their answers was zero, leading to their omission. Furthermore, Mahalanobis distance was used to detect outliers, four of which were excluded. Therefore, the 
Figure 1. The conceptual model.

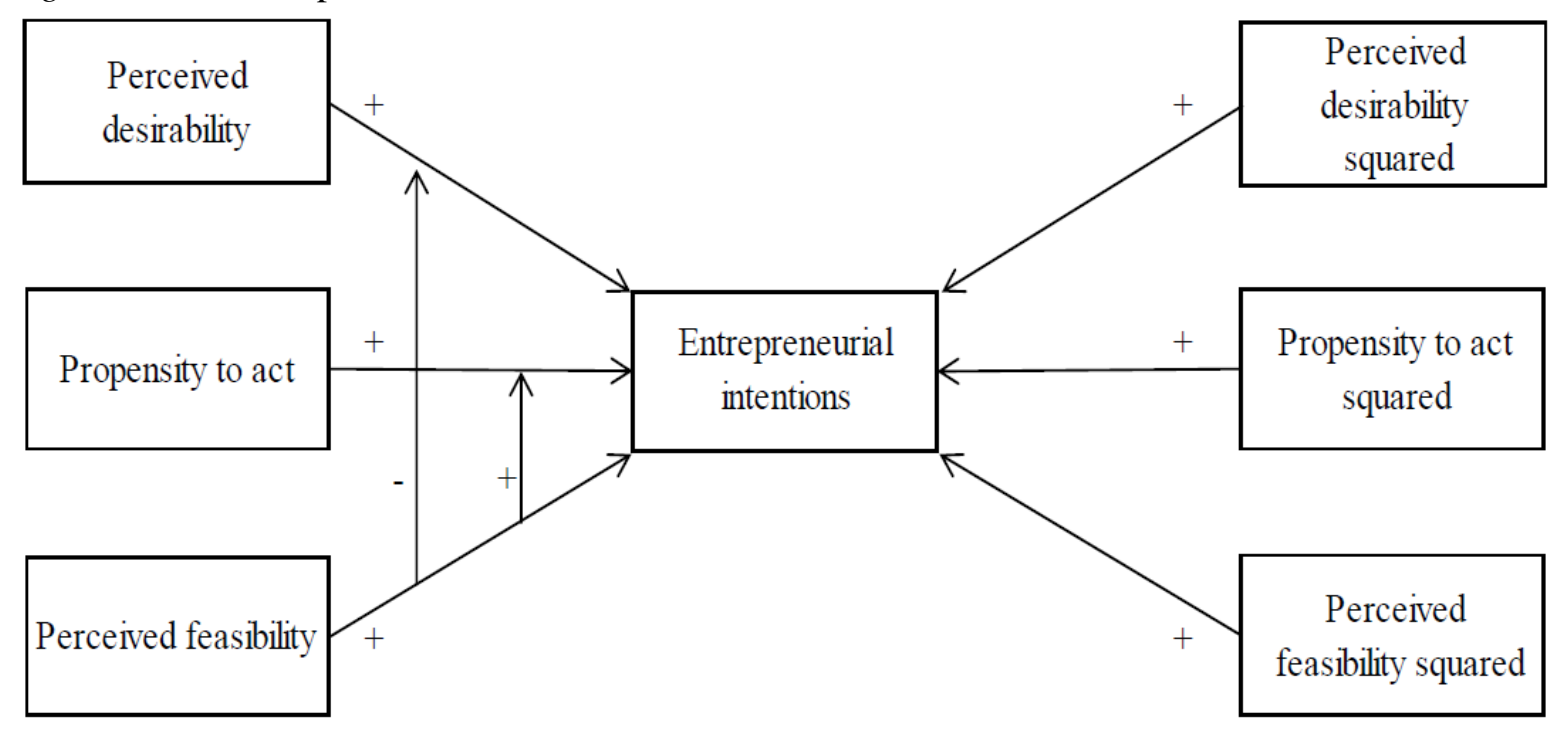

Figure 2. Scree plot.

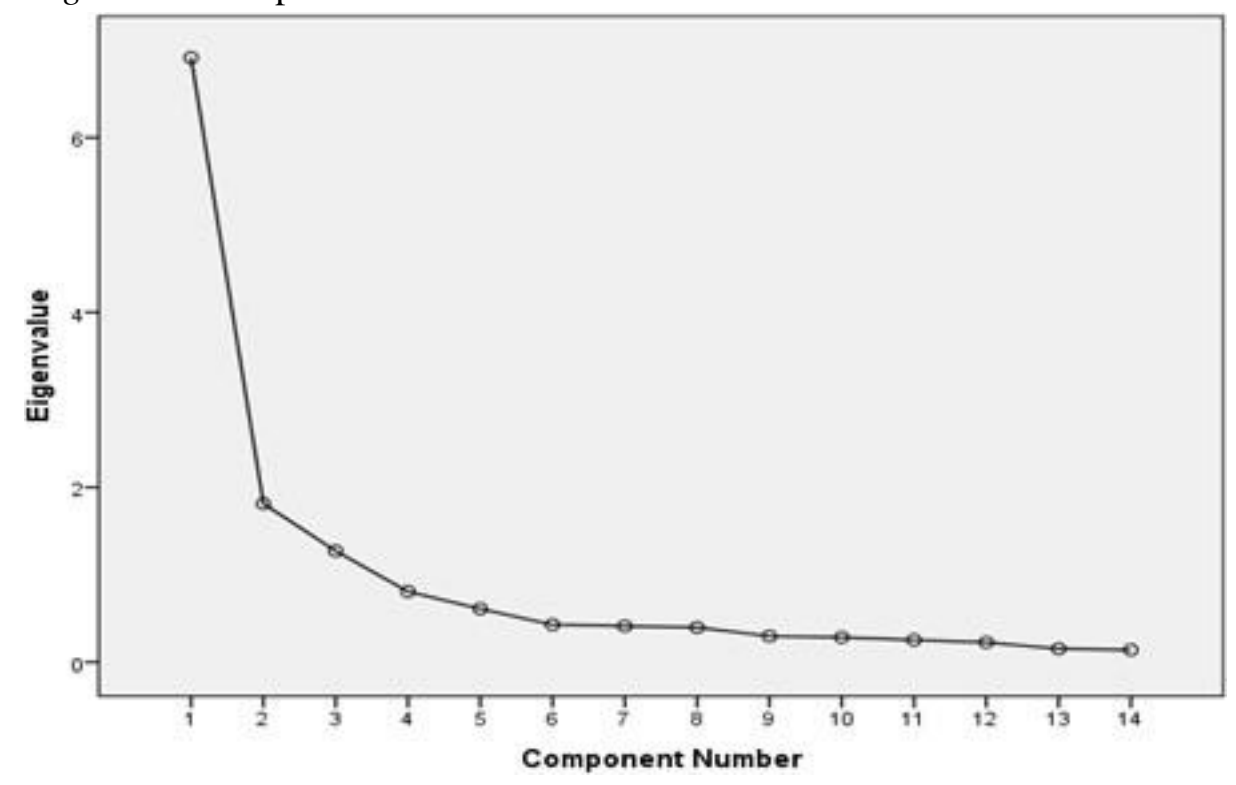

Source: Authors' calculation.

final sample consisted of a total sample size of 214 students, 133 of which were female students and 81 male.

The Kaiser-Meyer-Olkin measure (KMO) was calculated and the Bartlett test of sphericity was conducted to determine the adequacy of the data for factor analysis, the values which are shown in Table 1. Given that the KMO measure is 0.913 and that the null hypothesis of the Bartlett test of sphericity on all levels of significance $(\mathrm{p}=0.000)$ can be rejected, the data is appropriate for a factor analysis.

The results of the exploratory factor analysis are displayed in Table 4 in the appendix. Although the eigenvalue for one factor was slightly less than one, all other criteria suggest retaining four factors. Namely, the alternative principle of factor retention, Valicers' minimum average partial test, recommends the use of four factors, which is also in line with the scree plot shown in Figure 2. Furthermore, it is firmly theoretically established that the Shapero-Sokol model has four factors. 
Table 1. Values of indices.

\begin{tabular}{rrrrrrr}
\hline \hline Indices & KMO & Bartlett test & RMSEA & CFI & TLI & $\begin{array}{r}\text { LR test } \\
\left(\text { Chi }^{2}\right)\end{array}$ \\
\hline \hline & 0.913 & $2031.493^{* * *}$ & 0,008 & 0,999 & 0,998 & 72.00 \\
\hline
\end{tabular}

Source: Authors' calculation. ${ }^{* * *}$ means significant at $1 \%$ level.

Table 2. Correlation matrix

\begin{tabular}{lrrrr}
\hline \hline & \multicolumn{1}{c}{ 1. } & 2. & 3. & $\mathbf{4}$ \\
\hline 1. Perceived desirability & 1 & - & - & - \\
2. Perceived feasibility & 0.486 & 1 & - & - \\
3. Propensity to act & 0.495 & 0.564 & 1 & - \\
4. Entrepreneurial intentions & 0.756 & 0.571 & 0.379 & 1 \\
\hline \hline
\end{tabular}

Source. Authors' calculation.

Table 3. Results of the model.

\begin{tabular}{lrr}
\hline \hline & $\beta$ & $\mathrm{Z}$ \\
\hline Perceived desirability $\rightarrow$ Entrepreneurial intentions & $0.845^{* * * *}$ & 9.02 \\
Perceived feasibility $\rightarrow$ Entrepreneurial intentions & $0.471^{* * *}$ & 4.29 \\
Propensity to act $\rightarrow$ Entrepreneurial intentions & $-0.254^{*}$ & -1.75 \\
Perceived desirability squared $\rightarrow$ Entrepreneurial intentions & $0.036^{* *}$ & 2.35 \\
Perceived feasibility squared $\rightarrow$ Entrepreneurial intentions & $0.031^{* * *}$ & 3.49 \\
Propensity to act squared $\rightarrow$ Entrepreneurial intentions & $-0.017^{*}$ & -1.73 \\
Perceived desirability \& perceived feasibility $\rightarrow$ Entrepreneurial intentions & $0.192^{* * *}$ & 2.77 \\
Propensity to act \& perceived feasibility $\rightarrow$ Entrepreneurial intentions & $0.174^{* *}$ & 2.17 \\
\hline \hline
\end{tabular}

Source: Authors' calculation. ${ }^{* * *}$ means significant at $1 \%$ level. ${ }^{* *}$ means significant at $5 \%$ level.

* means significant at $10 \%$ level.

The loadings of all latent constructs have exceeded the recommended cut-off value of 0.7. In addition, the reliability and validity of constructs were checked. All four latent variables have a Cronbach $\alpha$ coefficient larger than the recommended value of 0.7 , indicating that the factors are consistent. For testing validity, average variance extracted and composite reliability were calculated. Convergent validity is established since the values of average variance extracted and composite reliability are above the suggested value of 0.7 . Discriminant validity is demonstrated by stating the values of the average variance extracted which are bigger than the squared correlation coefficients in Table 2.

After the exploratory factor analysis, confirmatory factor analysis was carried. Widely used measures for testing the overall goodness of fit, namely the root mean square error of approximation (RMSEA), the LR test of the saturated model, the comparative fit index (CFI) and the Tucker-Lewis index (TLI), are found in Table 1. The overall goodness of fit can be determined from the following four criteria, namely that the values of the CFI and the TLI exceed 0.95, that RMSEA is below 0.05 and that the null hypothesis of the LR test $(\mathrm{p}=0.444)$ cannot be rejected. It is worth noting that there are no multicollinearity problems given that all variance inflation factors are below 0.5 .

The results of path coefficients are shown in Table 3. Perceived desirability has a positive statistically significant impact on entrepreneurial intentions on all levels of significance $(\mathrm{p}=0.000)$, meaning that as students tend to find entrepreneurship a more desirable option, there is an increase in their entrepreneurial intention. The same can be said about perceived feasibility, with regards to the level of significance $(\mathrm{p}=0.000)$ and the sign of the effect which is also positive. From this, it follows that students who believe that they have more of the necessary skills to be an entrepreneur, the higher their entrepreneurial intentions will be. An unanticipated 
result is found when looking at the propensity to act variable. The lowest impact of the propensity to act on entrepreneurial intentions $(\mathrm{p}=0.081)$ is expected, but the direction of that effect is not. This direction is negative, meaning that the more a student has a disposition to take entrepreneurial action the lower will his entrepreneurial intentions be.

A deeper understanding of these relations can be found when testing for nonlinear effects, all of which are statistically significant. The quadratic effect is positive for both perceived desirability $(\mathrm{p}=0.019)$ and perceived feasibility $(\mathrm{p}=0.000)$. This means that there is an upward trend given the overall positive impact of these constructs on entrepreneurial intentions, but the incremental effects of perceived desirability and feasibility on entrepreneurial intentions are increasing at their higher levels, respectively. The opposite was found for the propensity to act since the overall effect of the propensity to act was negative and its squared values were also found to have a negative impact ( $\mathrm{p}=0.084)$. The direction of this effect is the opposite of what was hypothesized.

Concerning the interaction term for perceived feasibility, the results show that perceived feasibility is a positive statistically significant moderator for both perceived desirability $(p=0.006)$, which was not hypothesized, and propensity to act ( $\mathrm{p}=0.03)$, which was hypothesized. In other words, the effect of perceived desirability and propensity to act on entrepreneurial intentions is contingent on the levels of perceived feasibility. Thus, the effect of students' perceived desirability on entrepreneurial intentions will be stronger the more they believe they have the required ability to become an entrepreneur. The same holds for their propensity to act.

\section{Concluding remarks}

This study uses the Shapero-Sokol model of an entrepreneurial event to determine what causes entrepreneurial intentions among undergraduate students. Both perceived desirability and perceived feasibility have been found to positively impact entrepreneurial intentions, which is in accordance with the literature. However, the negative effect of the propensity to act on entrepreneurial intentions was unforeseen. This means that the students who have lower inclinations towards entrepreneurial actions will have higher entrepreneurial intentions. One possible explanation for this result is that students in the sample can be classified as having highly lifestyle entrepreneurs' intentions, as opposed to growth entrepreneurs. Meaning, they are not focused on having high expanding and rapidly growing businesses.

A closer look into the mentioned relations reveals interesting results. Namely, all three quadratic effects were found to be statistically significant. For perceived desirability and perceived feasibility, this effect was positive. Therefore, there is a general upward trend, but for lower levels, these effects are decreasing and for higher levels, they are increasing. The opposite is found for propensity to act. From the results of the nonlinear analysis, it is possible to find support for the "too-much-of-a-good-thing" principle, given the negative quadratic effect of propensity to act. However, this result can be interpreted in the light of lifestyle entrepreneurial desires, so this meta principle can be rejected in this study.

Furthermore, the moderating effect of perceived feasibility was tested. This moderating effect was found to be positive for perceived desirability and propensity to act. Therefore, perceived desirability and propensity to act have a higher impact on entrepreneurial intentions when the levels of perceived feasibility are high. The positive effect of the perceived desirability perceived feasibility interaction term is not congruent with the previous finding so this relationship needs further examination.

Further academic research could broaden the theoretical and empirical facet of this subject. Using higher-order terms to test for additional curves, would establish more detailed parameters to be examined. Additionally, incorporating other moderators would advance knowledge of 
causal relations between the three proposed determinants of entrepreneurial intentions in the Shapero-Sokol model.

\section{Acknowledgments}

We would like to thank the Editor-In-Chief Francisco J. Delgado and the anonymous referees for their valuable comments and suggestions.

\section{References}

Bateman, T. S. and Crant, J. M. (1993) The proactive component of organizational behavior: A measure and correlates, Journal of Organizational Behavior, 14(2), 103-118.

Bernoster, I., Rietveld, C., Thurik, A. and Torrès, O. (2018) Overconfidence, Optimism and Entrepreneurship, Sustainability, 10(7), 2233.

Busenitz, L. W. and Barney, J. B. (1997) Differences between entrepreneurs and managers in large organizations: Biases and heuristics in strategic decision-making, Journal of Business Venturing, 12(1), 9-30.

Chung-Yan, G. A. and Butler, A. M. (2011) Proactive personality in the context of job complexity, Canadian Journal of Behavioural Science/Revue Canadienne Des Sciences Du Comportement, 43(4), 279-286.

Erikson, T. (2001) Revisiting Shapero: A taxonomy of entrepreneurial typologies, New England Journal of Entrepreneurship, 4(1), 9-14.

Esfandiar, K., Sharifi-Tehrani, M., Pratt, S. and Altinay, L. (2019) Understanding entrepreneurial intentions: A developed integrated structural model approach, Journal of Business Research, 94, 172-182.

Fitzsimmons, J. R. and Douglas, E. J. (2011) Interaction between feasibility and desirability in the formation of entrepreneurial intentions, Journal of Business Venturing, 26(4), 431- 440.

Grant, A. M. and Schwartz, B. (2011) Too Much of a Good Thing: The Challenge and Opportunity of the Inverted U, Perspectives on Psychological Science, 6(1), 61-76.

Herzberg, F. (1966) Work and the nature of man, Crowell: New York.

Jenkins, G. D. and Taber, T. D. (1977) A Monte Carlo study of factors affecting three indices of composite scale reliability, Journal of Applied Psychology, 62(4), 392-398.

Krueger, N. (2009) Entrepreneurial Intentions are Dead: Long Live Entrepreneurial Intentions. In Carsrud, A. L. and Brännback, M. (Eds.): Understanding the Entrepreneurial Mind, Springer: New York, 51-72.

Krueger, N. F. and Kickul, J. (2006) So You Thought the Intentions Model Was Simple? Cognitive Style and the Specification of Entrepreneurial Intentions Models, SSRN Electronic Journal.

Krueger, N. F., Reilly, M. D. and Carsrud, A. L. (2000) Competing models of entrepreneurial intentions, Journal of Business Venturing, 15(5-6), 411-432.

Newman, A., Obschonka, M., Schwarz, S., Cohen, M. and Nielsen, I. (2019) Entrepreneurial self-efficacy: A systematic review of the literature on its theoretical foundations, measurement, antecedents, and outcomes, and an agenda for future research, Journal of Vocational Behavior, 110, 403-419.

Phillips, J., Gully, S. M. and McCarthy, J. E. (2012) The Role of Proactive Personality, Goal Orientation \& Self-Efficacy in Goal Setting \& Performance, Academy of Management Proceedings, 2012(1), 15993.

Pierce, J. R. and Aguinis, H. (2013) The Too-Much-of-a-Good-Thing Effect in Management, Journal of Management, 39(2), 313-338. 
Ranga, V., Jain, S. and Venkateswarlu (2019) Exploration of Entrepreneurial Intentions of Management Students Using Shapero's Model, Theoretical Economics Letters, 9(4), 959-972. Shapero, A. and Sokol, L. (1982) Social dimensions of entrepreneurship. In Kent, C., Sexton, D. and Vesper, K. (Eds.): The encyclopedia of entrepreneurship. Prentice-Hall: Englewood Cliffs, 72-90.

Zhao, H. and Seibert, S. E. (2006) The Big Five personality dimensions and entrepreneurial status: A meta-analytical review, Journal of Applied Psychology, 91(2), 259-271.

\section{Appendix - Detailed information on variables used}

Table 4. Variables used

\begin{tabular}{|c|c|c|c|c|c|c|c|}
\hline Variable & Item & Loading & Cronbach $\alpha$ & $A V E$ & $C R$ & Eigen & $\begin{array}{r}\text { Var. } \\
\text { explained }\end{array}$ \\
\hline \multirow[t]{5}{*}{$\begin{array}{l}\text { Perceived } \\
\text { desirability }\end{array}$} & $\begin{array}{l}\text { I think that entrepreneur- } \\
\text { ship would have more } \\
\text { advantages than disad- } \\
\text { vantages for me }\end{array}$ & 0.835 & 0.932 & 0.745 & 0.935 & 6.913 & $49.376 \%$ \\
\hline & $\begin{array}{l}\text { Entrepreneurship is an } \\
\text { attractive choice for } \\
\text { my career }\end{array}$ & 0.817 & & & & & \\
\hline & $\begin{array}{l}\text { I would like to start my } \\
\text { own company if I had } \\
\text { the resources and the op- } \\
\text { portunity }\end{array}$ & 0.954 & & & & & \\
\hline & $\begin{array}{l}\text { Doing entrepreneurship } \\
\text { would give me satisfaction }\end{array}$ & 0.909 & & & & & \\
\hline & $\begin{array}{l}\text { Taking into account } \\
\text { other options, I would } \\
\text { like to pursue an entre- } \\
\text { preneurship } \\
\text { career }\end{array}$ & 0.790 & & & & & \\
\hline \multirow[t]{3}{*}{$\begin{array}{l}\text { Perceived } \\
\text { feasibility }\end{array}$} & $\begin{array}{l}\text { I know how to de- } \\
\text { velop an entrepreneur- } \\
\text { ial project }\end{array}$ & 0.872 & 0.818 & 0.724 & 0.887 & 1.272 & $9.082 \%$ \\
\hline & $\begin{array}{l}\text { I think I can con- } \\
\text { trol the process of } \\
\text { starting up a com- } \\
\text { pany }\end{array}$ & 0.826 & & & & & \\
\hline & $\begin{array}{l}\text { I think I know the neces- } \\
\text { sary details for founding } \\
\text { a company }\end{array}$ & 0.854 & & & & & \\
\hline \multirow[t]{3}{*}{$\begin{array}{l}\text { Propensity } \\
\text { to act }\end{array}$} & $\begin{array}{l}\text { If I start my own com- } \\
\text { pany, I will try to export } \\
\text { my oproduct as much as } \\
\text { possible }\end{array}$ & 0.794 & 0.748 & 0.651 & 0.848 & 0.806 & $5.76 \%$ \\
\hline & $\begin{array}{l}\text { If I start my own com- } \\
\text { pany, I will frequently } \\
\text { try to introduce new } \\
\text { products to } \\
\text { my customers }\end{array}$ & 0.843 & & & & & \\
\hline & $\begin{array}{l}\text { If I start my own com- } \\
\text { pany, I will frequently } \\
\text { try to } \\
\text { introduce new meth- } \\
\text { ods of production }\end{array}$ & 0.782 & & & & & \\
\hline
\end{tabular}




\begin{tabular}{|c|c|c|c|c|c|c|c|}
\hline \multirow[t]{3}{*}{ Intentions } & $\begin{array}{l}\text { I am seriously thinking of } \\
\text { running starting up my } \\
\text { own company }\end{array}$ & 0.904 & 0.918 & 0.791 & 0.919 & 1.812 & $12.945 \%$ \\
\hline & $\begin{array}{l}\text { I would like to commer- } \\
\text { cialize my business idea }\end{array}$ & 0.887 & & & & & \\
\hline & $\begin{array}{l}\text { I have a firm goal of } \\
\text { founding my own com- } \\
\text { pany }\end{array}$ & 0.877 & & & & & \\
\hline
\end{tabular}

Source: Authors' calculation. 